PAPER

\title{
Airflow patterns of voiced geminate stops in Japanese
}

\author{
Masako Fujimoto $^{1, *}$ and Seiya Funatsu ${ }^{2}$ \\ ${ }^{1}$ Advanced Research Center for Human Sciences, Waseda University, \\ Mikajima, 2-579-5 Tokorozawa, 359-1192 Japan \\ ${ }^{2}$ Science Information Center, Prefectural University of Hiroshima, \\ 1-1-71 Ujina-Higashi, Minami-ku, Hiroshima, 734-8558 Japan
}

(Received 1 April 2017, Accepted for publication 10 November 2017)

\begin{abstract}
Japanese voiced geminates have a tendency to devoice (e.g. baggu > bakku 'bag'). Voiced obstruents have inherent susceptibility for devoicing due to the aerodynamic voicing constraints (AVC), and the susceptibility is higher for geminate obstruents than singletons. As a way to investigate how Japanese speakers realize the contrast between the $[+/-$ voice] in obstruents, we examined oral and nasal airflow patterns during intervocalic voiced and voiceless stops in singletons and geminates. The results showed that no nasal airflow appeared during voiced and voiceless stops. Oral airflow showed asymmetry between single and geminate stops in realization of the stop voicing contrast. While the oral airflow pattern clearly differentiates the voiced vs. voiceless contrast in singletons, the patterns are similar in geminates. Acoustic signals also show the same asymmetry between the singletons and geminates. The observed convergence - a clear voicing contrast in singletons vs. a lack of the contrast in geminates, both in oral airflow and acoustic signals, indicate the tendency of neutralization of the voiced geminates into voiceless ones. Our results support the idea of phonetic and articulatory bases in phonological patterning of voicing neutralization in Japanese geminate stops.
\end{abstract}

Keywords: Voicing neutralization, Geminate stops, Japanese, Articulation, Oral/nasal airflow

PACS number: 43.70. $-\mathrm{h} \quad$ [doi:10.1250/ast.39.66]

\section{INTRODUCTION}

Japanese use both voicing and duration to realize phonological contrasts in obstruents. For example, 'ido' (water well) vs. 'ito' (thread) and 'kago' (mistake) and 'kako' (past) illustrate distinctions by /d/ vs. /t/, and /g/ vs. /k/, respectively; and 'ito' (thread) vs. 'itto' (one way) and 'ika' (below) vs. 'ikka' (a family) exemplifies a distinction by $/ \mathrm{t} / \mathrm{vs}$. /tt/, and / k/ vs. / kk/, respectively. Therefore, in theory, Japanese obstruents may exhibit fourway contrasts combining voicing and duration. However, in the actual Japanese lexicon, voiced geminates are limited to loanwords such as 'beddo' (bed), 'baggu' (bag) and 'doggu' (dog). It is well known that voiced geminates in these loan words can be pronounced as voiceless geminates (e.g., 'beddo' as [betto] and 'baggu' as [bakku]). The fact that these words are often written in Japanese orthography using the symbols for voiceless geminates as betto, bakku and dokku reflects the strong tendency of this neutralization.

*e-mail: m.fujimoto5@kurenai.waseda.jp
Previous acoustic studies reported that words with voiced geminates tend to be realized as partly voiceless sounds in standard Japanese [1,2], thus offering acoustic bases for phonological neutralization patterns in Japanese obstruents.

In the present study, we asked why such neutralization in the acoustic signal occurs, and approached this question from an aerodynamic perspective. According to Ohala, voiced obstruents have an inherent susceptibility for devoicing due to the aerodynamic voicing constraints (AVC), and the susceptibility is higher for geminate obstruents than singletons $[3,4]$. Based on the aerodynamic principle, the present study aims to examine airflow patterns during Japanese intervocalic voiced and voiceless stops with particular focus on examining (1) how airflow patterns differ between voiced and voiceless singleton stops and (2) whether such a difference persists in geminate stops as well.

The special focus is to investigate oral and nasal air flows. This choice was based on previous studies identifying three main strategies that speakers may use as ways to compensate for aerodynamic constraints; specifically, ways 
to maintain sufficient transglottal pressure difference, which lead to sustained transglottal airflow and thus sustained voicing. The first is to allow a small amount of air leakage through the oral tract by making incomplete oral closure [5]. This strategy results in spirantization of voiced stops. The second strategy is to allow a small amount of air leakage from the nasal tract by making incomplete velic closure [6,7]. This may result in audible (pre-)nasalization [8]. The third is to expand the vocal tract above the larynx, especially by using pharyngeal expansion or lowering the larynx as a way to reduce oral pressure [9-11]. This may result in audible pre-voicing of the stops. Since obtaining conclusive evidence for the third strategy requires imaging devices such as X-ray or MRI, this strategy is not examined in this study. By using airflow data, we investigated whether Japanese speakers use one of the first two strategies or possibly both. The research questions, therefore, are 1) does oral/nasal flow occur during closure of voiced/voiceless stops; 2) how, if at all, do the airflow patterns differ between singletons and geminates; and 3) do the airflow patterns account for the observed phonological neutralization of voiced geminates into voiceless ones?

\section{METHOD}

\subsection{Subjects and Materials}

Subjects were two Japanese, one male and one female, whose ages are 57 and 23 , respectively, at the time of recordings. Hereafter, the male subject is referred to as JM1 and the female, JF1. They were speakers of standard Japanese and were naïve to the purpose of the experiments. They were compensated for their time and the local traveling expenses.

Eight test words were selected for this study which contrast with intervocalic /d-t-dd-tt/ and /g-k-gg-kk/. They were non-words, except for 'kite' (come) and 'kitte' (stamps). Non-words were preferable for voiced geminates in order to avoid the possibility that speakers produce words from a mental lexicon, where the words with voiced stops might be represented with neutralized forms. Table 1 shows the test words.

Test words and filler words were randomized to derive 12 different lists, with each list including some of the test

Table 1 Test words. Target stops are marked with an underline. Note that $/ \mathrm{c} /$ is pronounced as [t, ] in Japanese.

\begin{tabular}{lll}
\hline Stops & Singleton & Geminate \\
\hline $\mathrm{t}$ & kite & kitte \\
$\mathrm{d}$ & kíde & kídde \\
$\mathrm{k}$ & cike & cikke \\
$\mathrm{g}$ & cige & cigge \\
\hline
\end{tabular}

words. All lists were written on sheets of (letter-size) paper in Japanese kata-kana syllabary and presented to the subjects. Subjects read each test word in a carrier sentence “(ee) sorede XX ni-suru." 'So, I make it XX.' Eight tokens for each test words were recorded.

\subsection{Airflow Data Acquisition}

All channels of airflow data were sampled with a $20 \mathrm{kHz}$ rate and $16 \mathrm{bits} / \mathrm{channel}$. The acoustic signal was recorded with an AKG C420 head-mounted microphone with M-Audio AudioBuddy preamplifier. The input signal was lowpass filtered with a $10 \mathrm{kHz}$ cutoff. Oral and nasal airflows were collected with a split oronasal Rothenberg mask, using Biopac TSD160A transducers and a Biopac DA100C amplifier interface. The signals were lowpass filtered with a $5 \mathrm{kHz}$ cutoff. The data acquisition system used the National Instruments PCI-6013 data acquisition hardware interface, and signals were acquired with the Matlab Data Acquisition Toolbox. All data were taken at the phonetic laboratory of the University of California, Berkeley.

\subsection{Data Analysis}

Data were analyzed using an original computer program that displays in a monitor (1) acoustic wave form, (2) sound spectrogram, (3) oral airflow and (4) nasal airflow. Figure 1 shows an example of analysis data for the token 'ee sorede cige nisuru' by JM1. Oral airflow (third row from top) and nasal airflow (bottom row) show the change in the amount liter per second $(l / \mathrm{s})$ of each flow as a function of the time varying speech articulation. The higher the point of the line, the greater volume of air is passing through the mask at that moment.

Segmentation was done by visual inspection of the speech wave and spectrogram using Praat [Ver. 6.0.22] [12] with window length 0.005 (s) and dynamic range $55.0 \mathrm{~dB}$ of spectrogram settings. Beginning and ending of the vowels are judged by the presence of clear energy of $F_{1}$ and $F_{2}$. The /i/-vowels following voiceless stops tend to reduce. In such a case, beginning and ending of periodic components were referred to. When no periodic components appear in the acoustic waveform and the spectrogram, the vowel is labeled as devoiced. The end point of a stop closure is determined by the presence of a spike of the release burst. When no burst appears in the spectrogram, the stop is labeled as spirantized.

\section{RESULTS}

\subsection{Acoustic Analysis}

\subsubsection{Vowel devoicing}

Vowel /i/ is devoiceable in the test words kite, kitte, cike and cikke. Table 2 shows the percentage where devoicing of $/ \mathrm{i} /$ occurred in the eight repetitions. In kite 


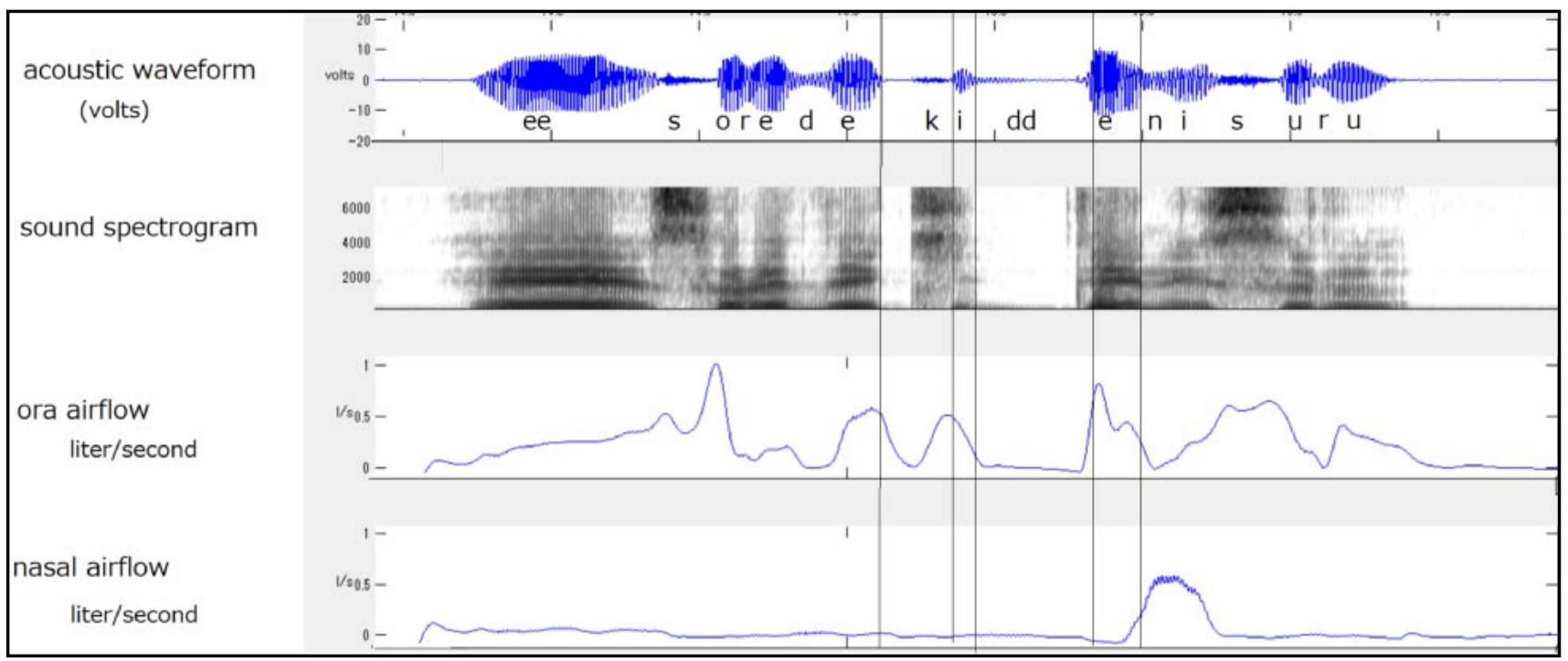

Fig. 1 An example of data. A waveform, sound spectrogram oral airflow and nasal airflow (from top to bottom) of 'ee sorede kidde nisuru' by JM1. Unit of oral/nasal flow is litter/second $(l / \mathrm{s})$. Frame length is 2 seconds.

Table 2 Rate of devoicing in $\%$ of $/ \mathrm{i} /$ and total number of tokens (in parenthesis) of the test words.

\begin{tabular}{lcc}
\hline Word & JM1 & JF1 \\
\hline cige & $0(8)$ & $0(8)$ \\
cike & $100(8)$ & $100(8)$ \\
cigge & $12.5(8)$ & $0(8)$ \\
cikke & $12.5(8)$ & $0(8)$ \\
kide & $0(8)$ & $0(8)$ \\
kite & $100(8)$ & $87.5(8)$ \\
kidde & $12.5(8)$ & $0(8)$ \\
kitte & $12.5(8)$ & $0(8)$ \\
\hline
\end{tabular}

and cike, /i/ was devoiced regardless of subject and tokens, except for one kite by JF1 in which a couple of weak pulses appeared for the duration of $13 \mathrm{~ms}$. However, for cikke and kitte, /i/ was not devoiced for either subject, except for one token each of kitte and cikke by JM1. This is in agreement with the previous findings that vowel devoicing occurs less frequently before geminates [13]. For cige, kide, cigge and kidde, /i/ was voiced across tokens for both subjects except for one token of kidde and cigge by JM1. This is noticeable because vowel devoicing before voiced geminates is atypical [13].

\subsubsection{Closure duration}

/g/ was spirantized in many tokens (75\% for JM1 and $62.5 \%$ for JF1) while /d/ was not. In case of spirantization, consonant duration is taken as the closure period of $/ \mathrm{g} /$ in the following analysis. For both subjects, the closure duration is longer in geminates than in singletons.

Averaged across subjects, closure duration is $0.043 \mathrm{~s}$ (0.079) for single voiced stop, $0.0711 \mathrm{~s}$ (0.0286) for single voiceless stop, $0.1942 \mathrm{~s}$ (0.0343) for geminate voiced stop, and $0.2055 \mathrm{~s}$ (0.0176) for geminate voiceless stops. Twoway ANOVA was performed with gemination (single or geminate) and voicing (voiced or voiceless) as independent variables and closure duration as dependent variable. The results showed that both gemination $(F(1,124)=1102.753$, $p=0.000)$ and voicing $(F(1,124)=20.851, p=0.000)$ are significant, but interaction was not significant $(p=$ $0.55)$. This indicates that the closure duration is longer in geminates than in singletons, and it is longer in voiceless stops than in voiced ones.

\subsubsection{Closure voicing}

Figure 2 compares the duration of the closure and voicing period. Voiceless stops were realized as voiceless for singletons and geminates regardless of tokens and subjects. Single voiced stops are fully or largely voiced for both subjects. However, in geminate voiced stops, closure period is often largely or half voiceless especially for JF1. These results indicate that, although the voicing contrast is apparent between single voiced- and voiceless pairs, it is less apparent between geminate pairs.

Table 3 shows the percentage of unvoicing during the closure of the stops calculated using Praat. Results of two-way AVOVA with gemination (single or geminate) and voicing (voiced or voiceless) as independent variables and percentage of unvoicing as dependent variable showed that gemination $(F(124,1)=110.634, p=0.000)$, voicing $(F(124,1)=31.557, p=0.000)$ and interaction $(F(124,1)=23.658, \quad p=0.000)$ were all significant. Namely, voiceless stops are more unvoiced than voiced ones and geminates are more unvoiced than singletons. Although the percentage differs considerably between voiceless and voiced stops in singletons, the difference 

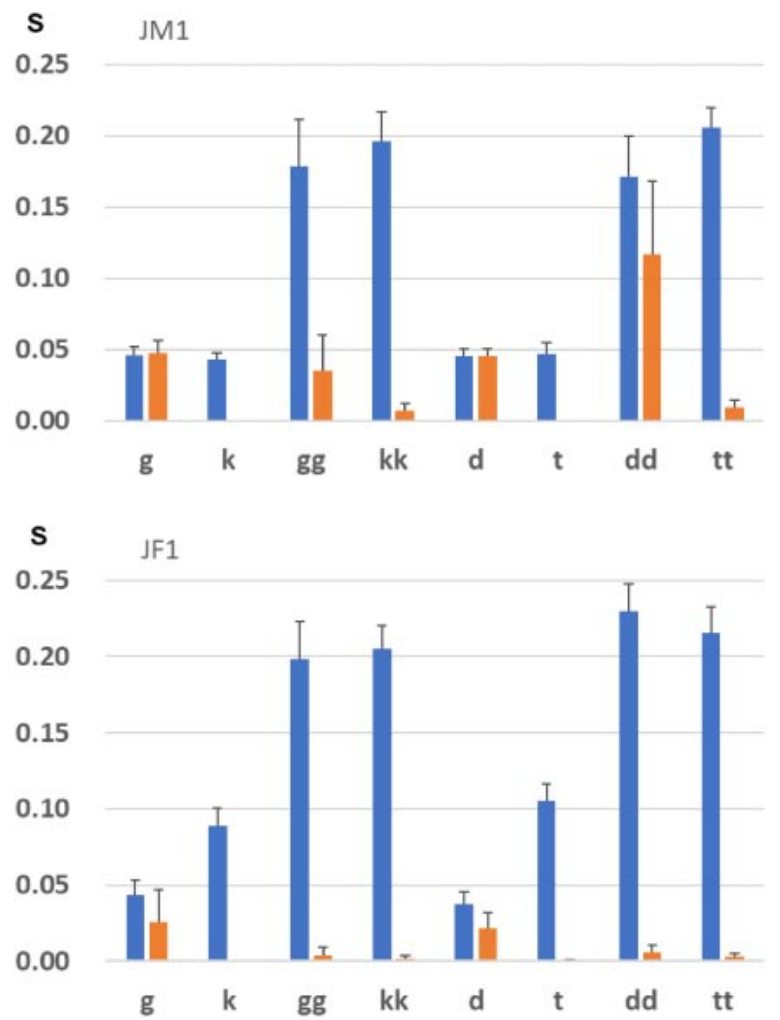

Fig. 2 Comparison of the closure duration (in blue) and voicing duration (in orange) of the stops in seconds. Error bars shows SD. Top panel shows the results for JM1 and bottom, JF1.

Table 3 Mean values and SD (in parenthesis) of the percentage of unvoicing during stop closure.

\begin{tabular}{lcc}
\hline & Voicing & Average (SD) \\
\hline \multirow{2}{*}{ Singletons } & voiced & $18.2(29.8)$ \\
\cline { 2 - 3 } & voiceless & $90.2(13.7)$ \\
\hline \multirow{2}{*}{ Geminates } & voiced & $67.2(41.3)$ \\
\cline { 2 - 3 } & voiceless & $93.7(4.9)$ \\
\hline
\end{tabular}

gets smaller in geminates. This indicates that the voicing contrast becomes vague in geminates, which presumably yields the significance of interaction.

3.1.4. Closure intensity

Figure 3 shows the intensity in $\mathrm{dB}$ during the stop closure. While intensity differs greatly between single voiced and voiceless stops, it is similar between geminate voiced and voiceless stops for both subjects.

Averaged across subjects, intensity was 73.8 (7.0) for single voiced stop, 61.5 (5.5) for single voiceless stops, 61.8 (4.1) for geminate voiced stops, and 61.0 (3.6) for geminate voiceless stops. The results of the two-way ANOVA with gemination (single or geminate) and voicing (voiced or voiceless) as independent variables and closure intensity as dependent variable showed that gemination
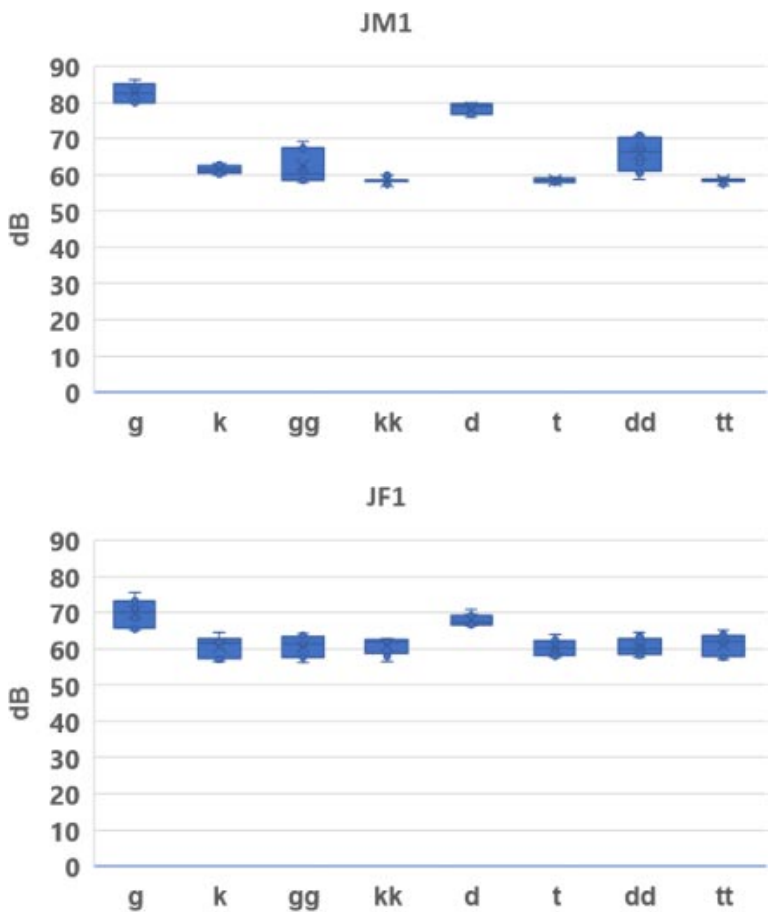

Fig. 3 Intensity in $\mathrm{dB}$ during the stop closure. Top panel is JM1 and bottom, JF1.

$(F(1,127)=55.015, \quad p=0.000), \quad$ voicing $\quad(F(1,127)=$ 59.432, $p=0.000)$ and interaction $(F(1,127)=36.175$, $p=0.000)$ were all significant. Intensity is larger in voiced stops than in voiceless ones, and it is larger in singletons than geminates. However, the difference between singletons and geminates narrowed in voiceless stops which presumably results in the significance of interaction.

\subsection{Airflow during Stops}

\subsubsection{Nasal airflow}

Figure 4 shows sample data during kide by JM1 and JF1. The third from top panel shows the transition of oral flow and the bottom panel, that of nasal flow. As is clear from the figures, the amount of nasal airflow increases only at the end of /e/ towards / $/ \mathrm{n}$ and stays around the zero line elsewhere including the stops of the test words. This shows that no nasal leakage appeared during the stop consonant. This pattern is consistent across test words, tokens and subjects. The result indicates that the two speakers did not exploit nasal venting as a strategy to maintain voicing during the voiced stops. It was true for geminates, too. Hereafter, nasal airflow is excluded from further analyses. 3.2.2. Oral flow

Oral airflow patterns were comparable across all eight tokens within each word and each speaker. Figure 5 shows examples of oral airflow (hereafter oral flow) patterns of the test words from JM1; and Fig. 6, those from JF1. While oral flow was suppressed during $/ \mathrm{t} /$ and $/ \mathrm{k} /$, it continued during $/ \mathrm{d} /$ and $/ \mathrm{g} /$. Although the flow gradually decreased 

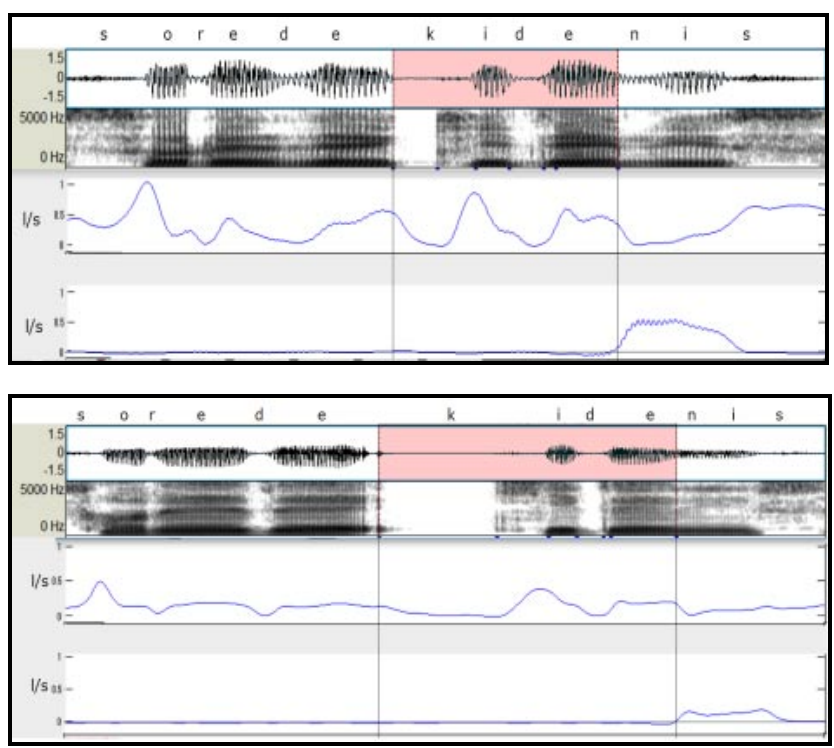

Fig. 4 Examples of [soredekidenis] part from 'sorede kide nisuru' by JM1 (top) and JF1 (bottom). Frame length is $1 \mathrm{~s}$ for JM1 and $1.2 \mathrm{~s}$ for JF1.

during the "closure" period, it did not completely stop before it increased again. These data suggest that the oral closure for single voiced stops was quite short or imperfect. The result is in agreement with the acoustic result that $/ \mathrm{g} /$ was generally spirantized.

These differences were generally absent in geminates. Oral flow was suppressed for both voiced and voiceless geminates throughout the closure period until the oral release occurred. Namely, oral flow of voiced geminates pattern together with voiceless geminates.

Table 4 and Fig. 7 show the amount of oral flow in litter/second $(l / \mathrm{s})$ during the stop closure. Oral flow is considerably less for JF1 than JM1. However, for both subjects, the flow shows less variation in geminates than in singletons.

Averaged across subjects, oral flow was $0.081(0.073)$ for single voiced stops, 0.813 (0.791) for single voiceless stops, $0.191(0.354)$ for geminate voiced stops, and 0.019 (0.011) for geminate voiceless stops. Figure 8 compares the voicing and gemination using pooled data. A two-way ANOVA was performed with gemination (singleton or geminate) and voicing (voiced or voiceless) as independent variables and amount of oral flow as dependent variable. The result showed that gemination was significant $(F(1,127)=38.036, \quad p=0.000)$. Voicing $(F(1,127)=$ $0.000, p=1.000)$ and interaction $(F(1,127)=0.001, p=$ $0.975)$ were insignificant. These results indicate that the amount of oral flow is significantly less in geminates regardless of voicing.

\section{DISCUSSION}

Some Japanese dialects (e.g. Tsugaru dialect in the
Table 4 Mean values and SD (in parenthesis) of oral flow in litter per second $(l / \mathrm{s})$.

\begin{tabular}{ccc}
\hline Phoneme & JM1 & JF1 \\
\hline g & $0.173(0.083)$ & $0.031(0.033)$ \\
$\mathrm{k}$ & $0.112(0.072)$ & $0.009(0.034)$ \\
$\mathrm{gg}$ & $0.012(0.004)$ & $0.010(0.005)$ \\
$\mathrm{kk}$ & $0.027(0.006)$ & $0.009(0.006)$ \\
$\mathrm{d}$ & $0.076(0.040)$ & $0.044(0.018)$ \\
$\mathrm{t}$ & $0.169(0.045)$ & $0.034(0.019)$ \\
$\mathrm{dd}$ & $0.017(0.006)$ & $0.037(0.071)$ \\
$\mathrm{tt}$ & $0.027(0.003)$ & $0.011(0.003)$ \\
\hline
\end{tabular}

Tohoku region) is known to be characterized by (pre-)nasalization for voiced obstruents [14]. In such a case, nasal flow is expected during or ahead of the target consonants. However, this was not the case for the present subjects. Oral flow was dominantly used across voiced and voiceless stops. The pattern of oral flow clearly differs between single voiced- and voiceless stops; it continues during voiced stops while it is suppressed during voiceless stops. On the other hand, the patterns are similar for voiced and voiceless geminates where oral flow was suppressed for a certain period during the closure.

The acoustic duration of the stop closure was longer in geminates than in singletons regardless of voicing. This agrees with the general description of the geminates in previous studies (e.g. [15]). However, intensity and voicelessness show asymmetry between single and geminate stops. Voicing of the stop closure was relatively shorter in voiced geminates, which may weaken the voicing contrast. While intensity of the closure is larger in voiced stops than in voiceless ones in singletons, it was similar in voiced and voiceless geminates.

Taken together, these results indicate that the lesser oral flow in voiced geminates weakens the voicing period of voiced geminate stops. This makes the distinction between voiced and voiceless geminates ambiguous. It, in turn, would lead to perceptional confusion between voiced and voiceless geminates and, ultimately, cause neutralization. The speakers of the present study utilize strategies to enhance phonological contrasts between single voicedvoiceless stops, but they fail to differentiate the geminate voiced-voiceless pairs.

The lesser oral flow during voiced geminates is presumably due to tighter linguo-palatal closure. Linguopalatal contact is not only longer but wider in stop geminates than in singleton counterparts in Japanese [16-19] as well as other languages such as Korean [19] and Berber [20]. Tighter linguo-palate contact commits to terminate vocal fold vibration and prevent the folds from vibrating. This would result in partial or full unvoicing of voiced geminates. 


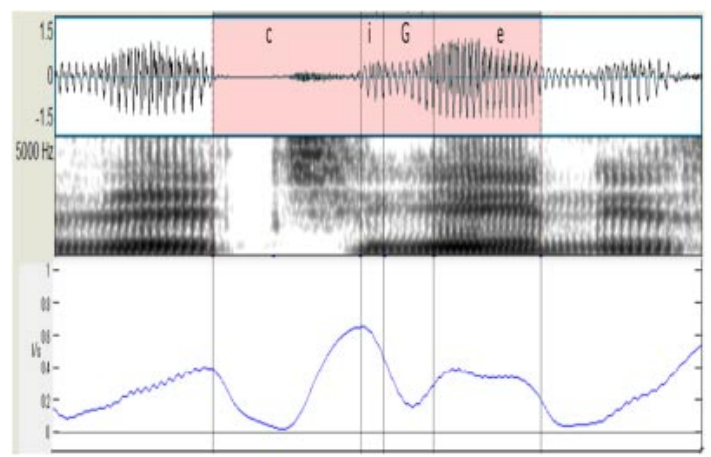

cige

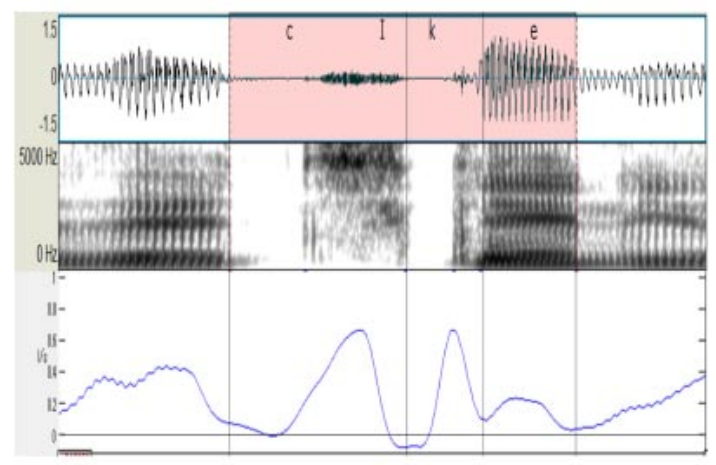

cike

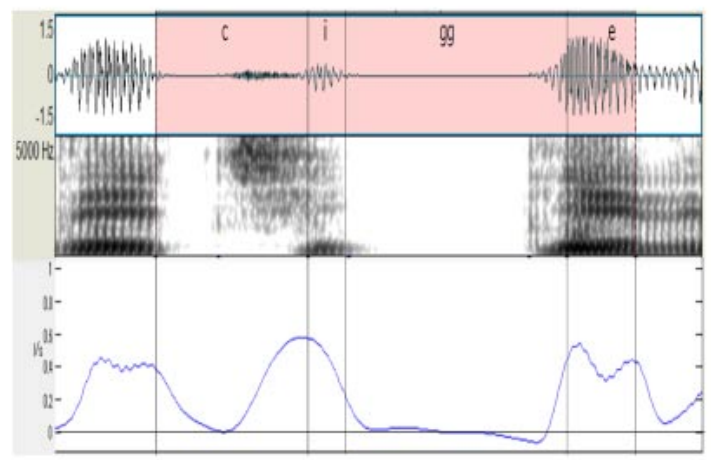

kidde

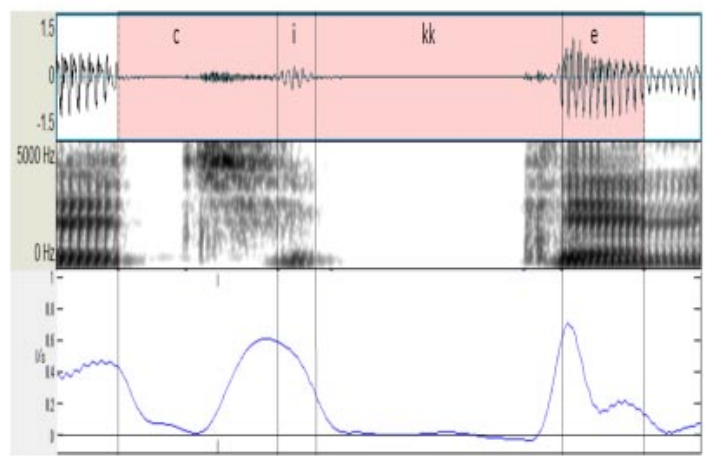

cikke

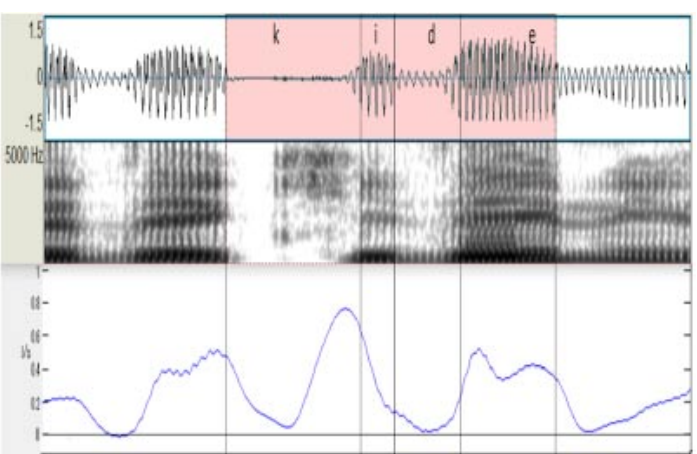

kide

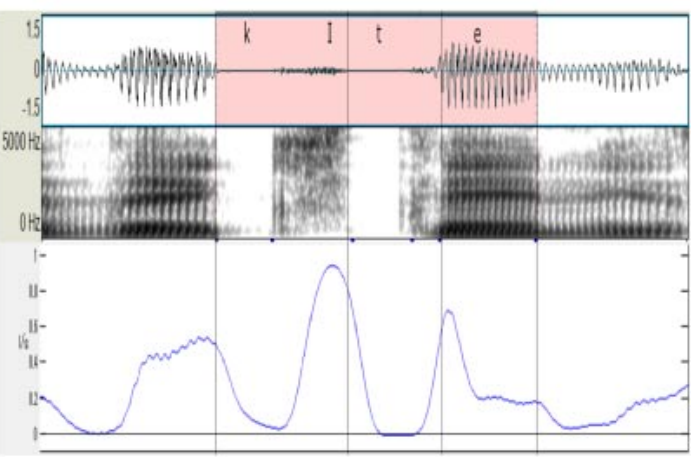

kite

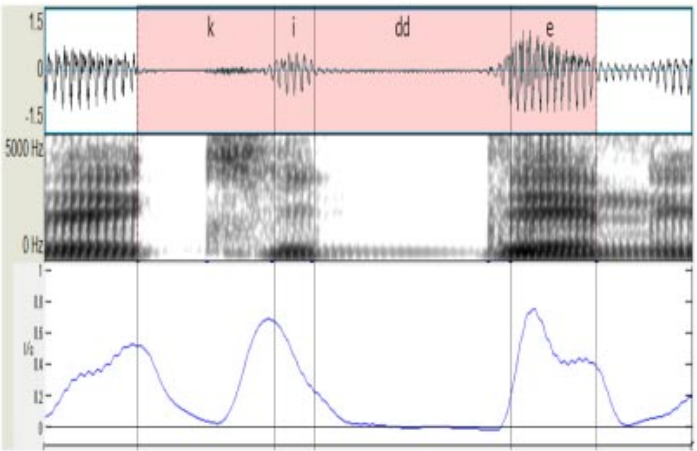

cigge

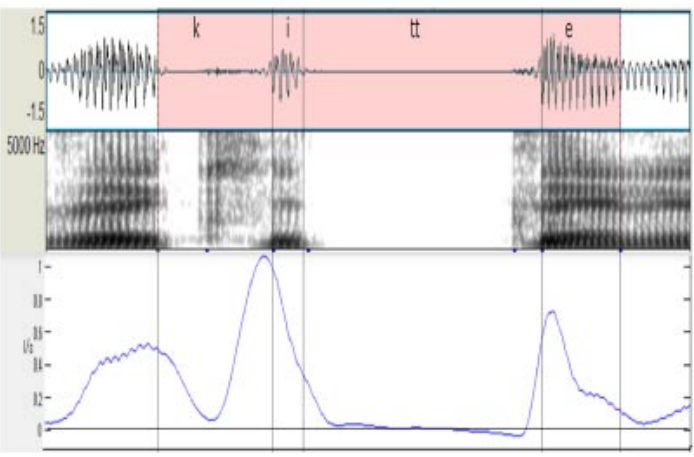

kitte

Fig. 5 Examples of speech wave, sound spectrogram and oral airflow of cige, cike, cigge and cikke (left column from top to bottom) and kide, kite, kidde and kitte (right column from top to bottom) by JM1. Each frame shows $600 \mathrm{~ms}$. Devoiced /i/ and spiratized /g/ are denoted by [I] and [G], respectively. 


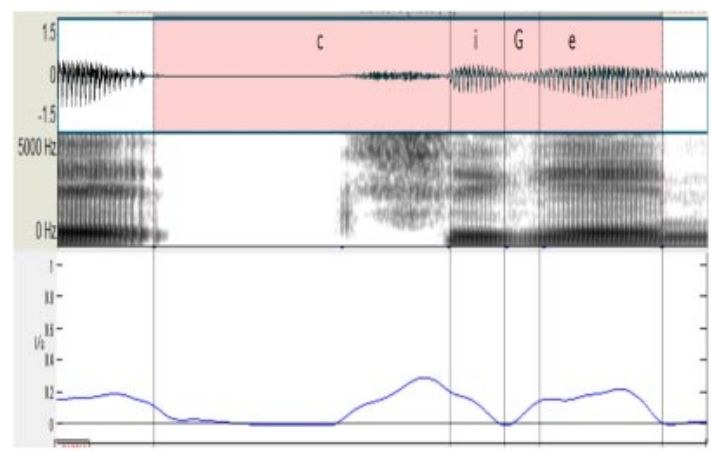

cige

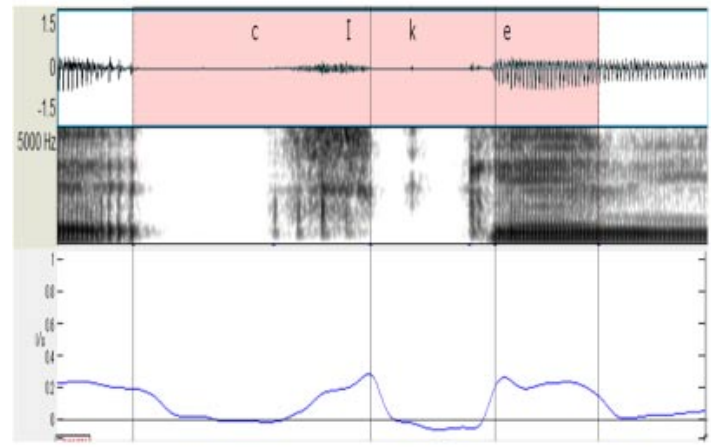

cike

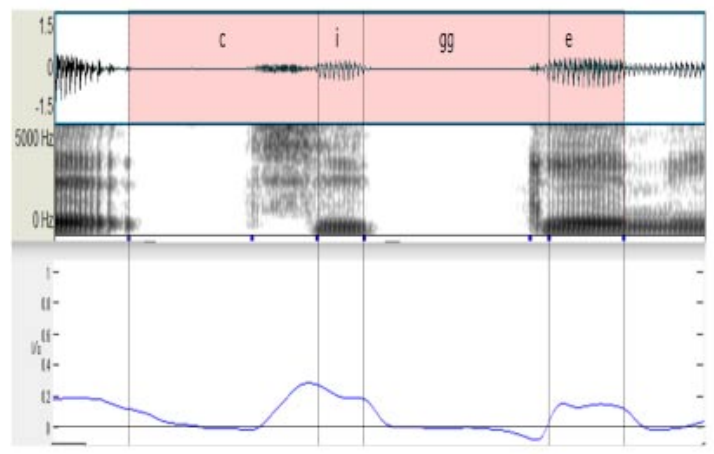

cigge

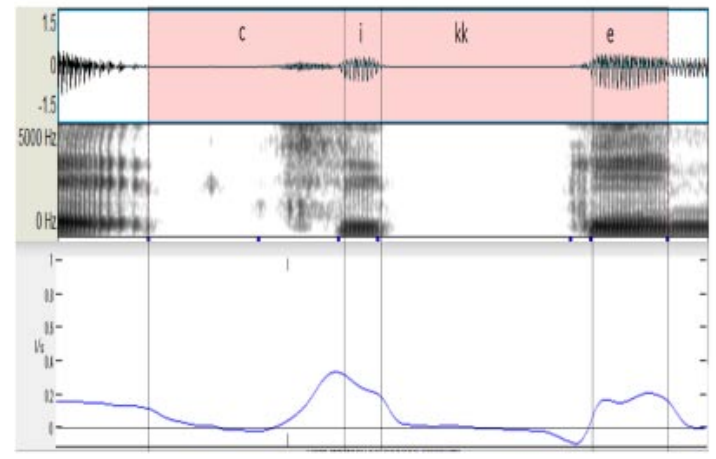

cikke

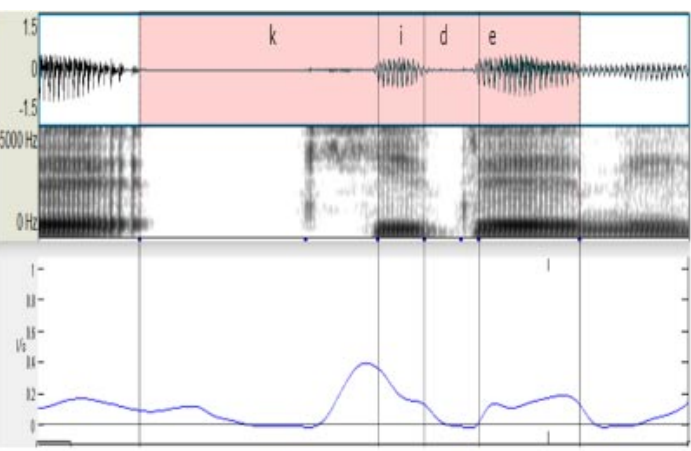

kide

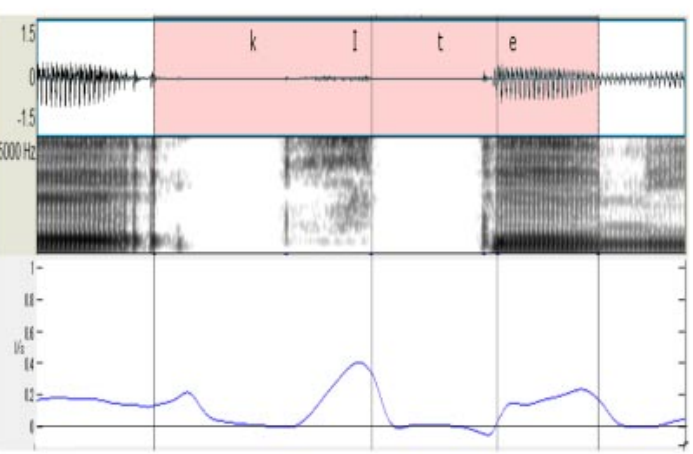

kite

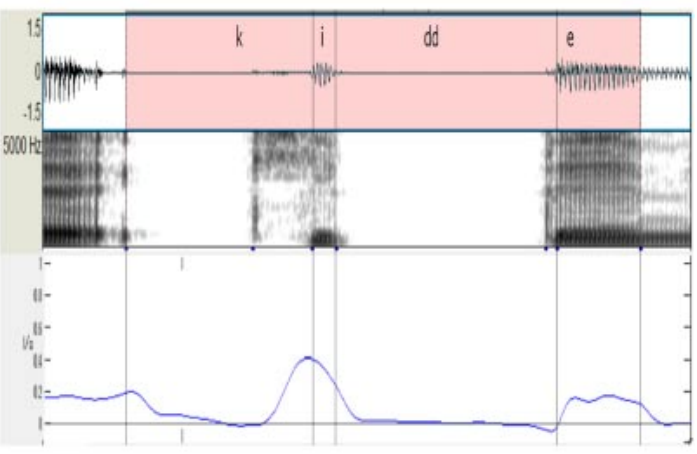

kidde

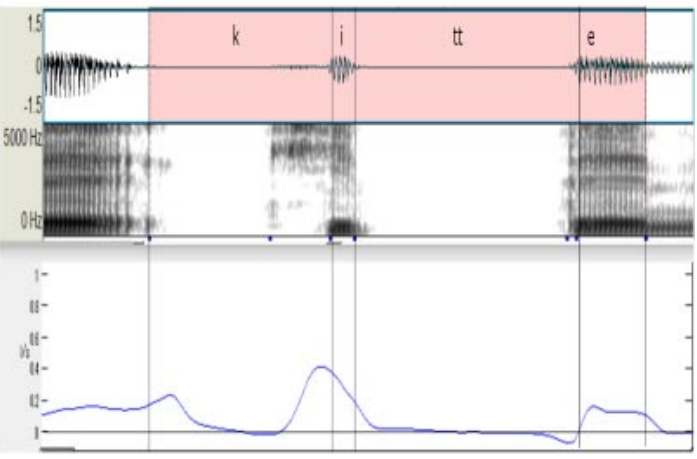

kitte

Fig. 6 Examples of speech wave, sound spectrogram and oral airflow of cige, cike, cigge and cikke (left column from top to bottom) and kide, kite, kidde and kitte (right column from top to bottom) by JF1. Each frame shows 700 ms. Devoiced /i/ and spiratized /g/ are denoted by [I] and [G], respectively. 

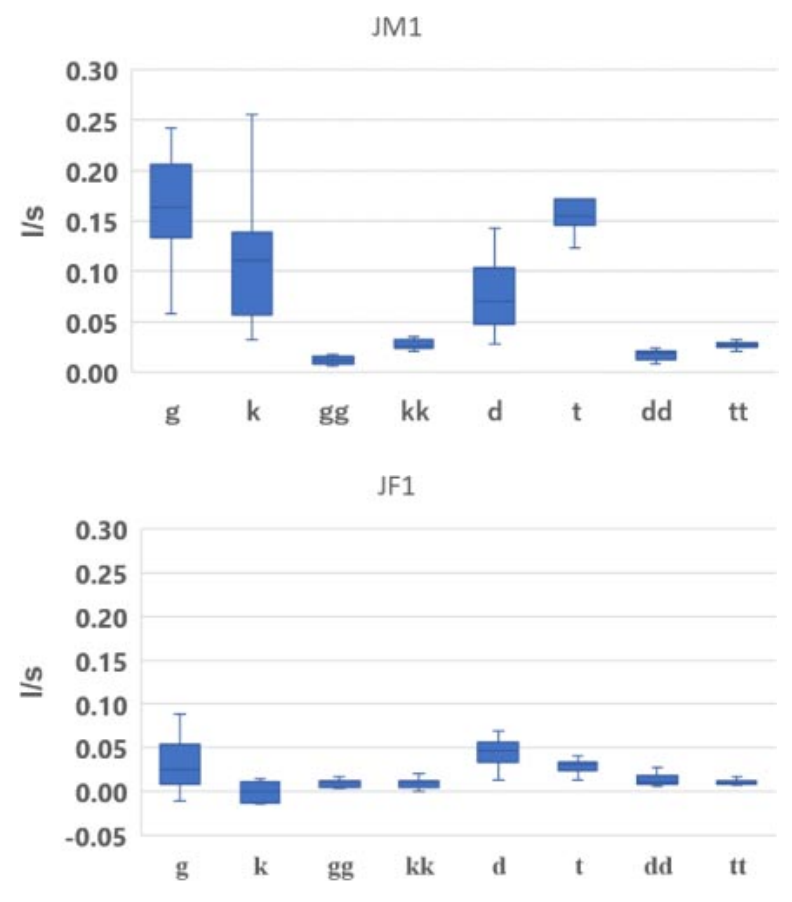

Fig. 7 Oral airflow $(l / \mathrm{s})$ during stop closure of JM1 (top) and JF1 (bottom).

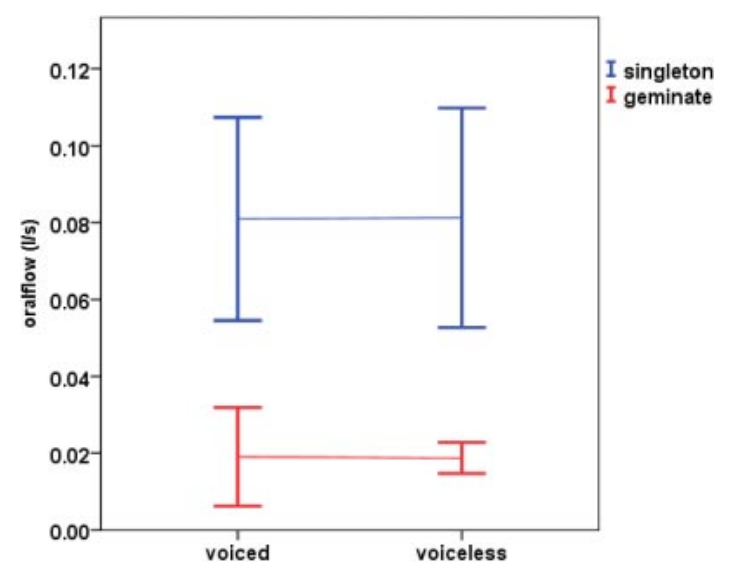

Fig. 8 Comparison of oral flow during stop closure. Error bar shows $95 \%$ confidence intervals.

As noted earlier, voiced geminates are limited to loan words in the lexicon in standard Japanese. Thus, speakers of standard Japanese may not be well experienced in using articulatory organs necessary to keep strong voicing throughout a long obstruent. This might be a possible linguistic basis that allows for unvoicing of voiced geminates.

Interestingly, in some Southern Ryukyuan dialects, voiced geminates are used phonologically in the core part of the lexicon as in 'vva' (you) and 'zzu' (fish) [21,22]. The speakers of the dialects clearly differentiate the voiced and voiceless geminates acoustically and articulatorily. MRI data showed that the speakers of such dialects expand the pharyngeal cavity during voiced geminates, presumably as

a way to maintain vocal fold vibration [23,24]. As for standard Japanese, no articulatory study seems to have been done on voiced geminates. Additional articulatory examination is necessary from this perspective.

Although the subjects and test words are limited, the present study sheds light on the articulatory basis of neutralization of a voiced geminate into voiceless ones. Further study involving more subjects and consonants is necessary to evaluate the current findings.

\section{CONCLUSIONS}

Nasal flow did not occur during voiced stops as well as voiceless ones. Oral flow was dominantly used in distinguishing voiced-voiceless contrast. However, there was asymmetry between single and geminate stops in realizing the voiced vs. voiceless contrast. While the oral flow pattern clearly differed between the voiced and voiceless segments in single stops, they were similar in geminates. Such asymmetry was reflected in acoustic patterns. Hence, the speakers utilize strategies to enhance phonological contrasts between single voiced-voiceless stops, but they fail to differentiate geminate voiced-voiceless pairs. This suggests an articulatory base for the neutralization of voiced geminates into voiceless ones.

\section{ACKNOWLEDGEMENTS}

This study was supported by JSPS KAKENHI (23520539, 26370470 and 15K02524) and MEXT, Japan. We thank Ronald Sprouse at the Phonology Lab at UC Berkeley for technical support for data acquisition devices and providing the program, and Reiko Kataoka for the preparation of the experiment and useful advice. Part of this study was presented at the 5th joint meeting of ASA and ASJ at Hawaii, USA.

\section{REFERENCES}

[1] S. Kawahara, "A faithfulness ranking projected from a perceptibility scale: The case of [+voice] in Japanese," Language, 82, 536-574 (2006).

[2] T. Matsuura, "Miyako shohogen no onseijitugen ni kansuru yobiteki kento [Preliminary study on phonetic realization in Miyako dialects]," in General Study for Research and Conservation of Endangered Dialects in Japan: Research Report on Miyako Ryukyuan, N. Kibe, Ed. (National Institute for Japanese Language and Linguistics, Tokyo, 2012), pp. 111-126 (in Japanese).

[3] J. Jaeger, "Speech aerodynamics and phonological universals," Proc. $4^{\text {th }}$ Annu. Meeting Berkeley Linguistics Soc., pp. 311329 (1978).

[4] J. Ohala, "Aerodynamics of phonology," Proc. 4th Seoul Int. Conf. Linguistics, pp. 92-97 (1997).

[5] S. Fuchs and P. Perrier, "An EMMA/EPG study of voicing contrast correlates in German," Proc. 15th Int. Congr. Phonetic Sciences, Universitat AutÒnoma de Barcelona, pp. 1057-1060 (2003).

[6] J. Ohala and M. Ohala, "The phonetics of nasal phonology: theorems and data," in Nasals, Nasalization, and the Velum, 
Vol. 5: Nasalization Velopharyngeal Function, M. K. Huffman and R. A. Krakow, Eds. (Academic Press, San Diego, 1993), pp. 226-249.

[7] M.-J. Solé, "Compatibility of features and phonetic content. The case of nasalization," Proc. ICPhS XVI, Saarbrücken, Germany, pp. 261-266 (2007).

[8] D. W. Warren, R. M. Dalston and R. Mayo, "Hypernasality and velopharyngeal impairment," Cleft Palate-Craniofacial J., 31, 257-262 (1993).

[9] J. S. Perkel, Physiology of Speech Production: Results and Implications of a Quantitative Cineradiographic Study, (MIT Press, Cambridge, Mass., London, 1969).

[10] J. Ohala and C. Riordan, "Passive vocal tract enlargement during voiced stops," Proc. Acoust. Soc. Am. Annu. Meet. Spring, J. Acoust. Soc. Am., 65, Suppl. 1, S23 (1979).

[11] J. Westbury, "Enlargement of the supraglottal cavity and its relation to stop consonant voicing," J. Acoust., Soc. Am., 73, 1322-1336 (1983).

[12] P. Boersma and D. Weenink, Praat: Doing phonetics by computer [Computer program]. Version 6.0.22, retrieved 15 November 2016 from http://www.praat.org/ (2016).

[13] M. Fujimoto, "Vowel devoicing," in The Handbook of Japanese Phonetics and Phonology, H. Kubozono, Ed. (De Gruyter, Berlin, 2015), pp. 167-214.

[14] K. Sato, I. Oshima, M. Oono, M. Kuno, M. Kuno, Y. Hirasawa and Y. Kushibiki, Aomori-ken no Kotoba [Language in Aomori Prefecture], T. Hirayama, I. Oshima, M. Oono, M. Kuno, M. Kuno, T. Sugimurao and K. Sato, Eds. (Meiji Shion, Tokyo, 2003) (in Japanese).

[15] S. M. Han, "Acoustic manifestations of mora timing in Japanese," J. Acoust. Soc. Am., 96, 73-82 (1997).

[16] NINJAL, Nihongono Boin, Shiin, Onsetsu: Choon Undo no
Jikken Onsegakuteki Kenkyu [Japanese Vowels, Consonants and Syllables: Experimental Study of Articulation], Ninjal report 100, (Shuei-shuppan, Tokyo, 1990) (in Japanese).

[17] A. Kochetov, "Voicing and tongue-palate contact differences in Japanese obstruents," J. Phon. Soc. Jpn., 18, 63-76 (2014).

[18] T. Matsui, S. Kawahara and J. Shaw, "EPG o mothiita nihongo shikeion no tyouontekitokutyo [Articulatory characteristic of Japanese palato-alveolar geminates by means of EPG," Proc. 90th Anniv. and 30th Gen. Meet. Phon. Soc. Jpn., pp. 132-137 (2016).

[19] A. Kochetov and Y. Kang, "Supralaryngeal implementation of length and laryngeal contrasts in Japanese and Korean," Can. J. Linguist., 62, 18-55 (2017).

[20] R. Ridouane, "Gemination in Tashlhiyt Berber: An acoustic and articulatory study," J. Int. Phon. Assoc., 37, 119-142 (2007).

[21] N. Kibe, Ed., General Study for Research and Conservation of Endangered Dialects in Japan: Research Report on Miyako Ryukyuan, NINJAL Collaborative Research Project Reports, 12-02 (National Institute for Japanese Language and Linguistics, Tokyo, 2012) (in Japanese).

[22] M. Fujimoto and S. Shinohara, "Consonants and vowels in Ikema variety of Miyako Rykyuan," Proc. Spring Meet. Acoust. Soc. Jpn., pp. 363-364 (2016).

[23] M. Fujimoto and S. Shinohara, "Articulation of voiced geminate and word-initial geminate obstruents in the Miyakojima Ikema dialect of Ryukyuan: A real-time MIR analysis," GemCon, Glasgow, pp. 27-28 (2015).

[24] M. Fujimoto and S. Shinohara, "Articulatory manifestation for voiced geminates and initial geminates in Ikema Ryukuan," Abstr. Methods Dialectol., XVI, Tachikawa, Japan, 1 page (2017). 